\title{
Bone Scan Index Is a Prognostic Factor for Breast Cancer Patients with Bone Metastasis Being Treated with Zoledronic Acid
}

\author{
Yukinori Okada1, Tatsuyuki Abe1, Yasuo Nakajima1, Itsuko Okuda², Brandon D. Lohman', \\ Yoshihide Kanemaki ${ }^{3}$, Yasuyuki Kojima ${ }^{4}$, Kouichirou Tsugawa ${ }^{4}$ \\ ${ }^{1}$ Department of Radiology, St. Marianna University School of Medicine, Kawasaki, Japan \\ ${ }^{2}$ Department of Diagnostic Radiology, International University of Health and Welfare, Mita Hospital, Tokyo, \\ Japan \\ ${ }^{3}$ Department of Radiology, Breast and Imaging Center, St. Marianna University School of Medicine, Kawasaki, \\ Japan \\ ${ }^{4}$ Department of Surgery, Division of Breast and Endocrine Surgery, St. Marianna University School of Medicine, \\ Kawasaki, Japan \\ Email: igaueno512@yahoo.co.jp
}

Received 7 August 2015; accepted 8 September 2015; published 11 September 2015

Copyright (C) 2015 by authors and Scientific Research Publishing Inc.

This work is licensed under the Creative Commons Attribution International License (CC BY).

http://creativecommons.org/licenses/by/4.0/

(c) (i) Open Access

\section{Abstract}

Bone scan index (BSI) has been used to quantify the spread of bone metastasis and be a prognostic indicator in prostate cancer with bone metastases. However, the utility of BSI in breast cancer patients with bone metastasis has not been yet established. We retrospectively reviewed 57 female breast cancer patients with osteoblastic/lytic combined type bone metastases and treated with zoledronic acid after bone metastasis was identified. Serial bone scintigrams were taken at the time of bone metastasis detection and during the 6- and 12-month follow-ups. The scintigrams were analyzed by BONE NAVI ${ }^{\mathrm{TM}}$ version 1 and the BSI value was calculated. Additionally, serum cancer antigen 15-3 (CA15-3) and carcinoembryonic antigen (CEA) were measured. The patients were divided in 2 distinct groups-group A representing all follow-up BSI values $\leq$ initial BSI values and group B representing all follow-up BSI values $\geq$ initial BSI values. The interval changes of CA15-3 and CEA were divided in the same fashion. Kaplan-Meier method and log-rank test revealed that the overall survival rate was significantly greater in group A than those of group B after 6 months $(p=0.011)$ and 12 months $(p=0.016)$. Univariate analysis revealed that the overall survival rate was significantly greater in group A than those of group B, after a 6 month period (Hazard Ratio [HR] 5.841; 95\% confidence interval [CI] $1.248-27.34 ; p=0.025$ ) and 12 month period (HR: 4.22; 95\% CI 1.17615.15; $p=0.027$ ). Multivariate analysis demonstrated that BSI changes after 6 and 12 months trended toward significance regarding parameters affecting survival rate (age and CA15-3) with a HR $=12.760(95 \% \mathrm{CI} 1.8110-89.850)$ at 6 months with a $p=$ 
0.010 and a HR $=5.0640(95 \% \mathrm{CI} 1.0590-24.220)$ at 12 months with a $p=0.042$. BSI changes after 6 and 12 months appear to be a prognostic factor in breast cancer patients with bone metastasis treated with zoledronic acid.

\title{
Keywords
}

\author{
Bone Scintigraphy, Bone Scan Index, Zoledronic Acid, Overall Survival Rate
}

\section{Introduction}

Breast cancer is currently the most common type of cancer among Japanese women. Bone is the second most common site of metastasis and is often associated with a poor outcome [1] [2]. The diagnosis of bone metastasis is based on clinical symptoms, blood examination, and radiology imaging such as computed tomography (CT), magnetic resonance imaging (MRI), and plain X-rays. Bone scintigraphy is a useful screening tool that allows systemic visual evaluation of the entire skeleton within a single scan and has a sensitivity and specificity of 98.0\% and 93.5\% in the case of breast cancer [3] [4]. When assessing bone metastases, scintigraphy relies on imaging findings, which records the distribution and uptake patterns of the ${ }^{99 \mathrm{~m}}$ Tc-Methyl diphosphonate $\left({ }^{99 \mathrm{~m}}\right.$ Tc-MDP) or ${ }^{99 \mathrm{~m}} \mathrm{Tc}-$ Hydroxymethylene diphosphonate $\left({ }^{99 \mathrm{~m}} \mathrm{Tc}-\mathrm{HMDP}\right)$ radioactive tracers within the skeletal system. However, this imaging modality lacks objectivity and makes it difficult to compare serial changes on follow-up scans. Recently, computer-aided diagnosis (CAD) software has become a part of the routine involved in the detection and differential diagnosis of various types of abnormalities in medical imaging. Its practical aspects as well as its objective approach when interpreting diagnostic images indicate that it may become an increasingly utilized tool when diagnosing bone metastases. BONE NAVI ${ }^{\mathrm{TM}}$ version 1 (FUJI RI pharma Co. Ltd. Tokyo Japan) is specifically designed, commercially available CAD software that analyzes and interpret bone scintigraphy. BONE NAVI ${ }^{\mathrm{TM}}$ version 1 has been reported to significantly assist and improve the accuracy of scintigraphy diagnosis even for the most experienced radiologist [5], and automatically calculates the BSI, which is a value that expresses the tumor burden in bone as a percent of the total skeletal mass based on the reference table of normal skeletal masses. The BSI was developed as a quantitative tool to improve the interpretability and clinical relevance of the bone scintigraphy [6]. Changes of BSI were reported to be a better predictor of patient survival than changes in prostate specific antigen (PSA) value in patients with prostatic cancer with bone metastases [7]. Like prostate cancer, bone metastasis from breast cancer is the most common scenario and significantly affects patients' survival. However, to our knowledge, there are few reports in the literature comparing BSI changes and survival rates in breast cancer patients. This retrospective study is aimed at examining these relationships and elucidating the role of BSI in breast cancer patients with bone metastasis.

\section{Patients and Methods}

\subsection{Patients}

We reviewed the radiological information system and medical history charts and we selected 57 breast cancer patients who were newly diagnosed with bone metastasis between January 1, 2006 and October 27, 2012. The patients had a median age of 56 years (range, 32 - 78 years) at the time bone metastasis was detected and confirmed by clinical follow-up and/or MRI and CT imaging. Extra osseous metastases at onset of bone metastasis were detected in 31 subjects. CT scan imaging revealed that all bone metastases were osteoblastic/lytic combined types. The breast cancer subtypes were Luminal A/B $(n=46 ; 80 \%)$, HER2 ( $n=7 ; 12.2 \%)$, Basal-like ( $n=$ 3; 5.2\%) and unknown $(\mathrm{n}=1 ; 1.8 \%)$.

All patients were administered hormonal (Tamoxifen, Fulvestrant, and Leuprorelin) or chemotherapeutic (Capecitabine, Gemcitabine, docetaxel, Paclitaxel, trastuzumab, and FEC100) treatment or a combination of both as soon as bone metastases were diagnosed. In addition, all patients were immediately treated with zoledronic acid, once bone metastasis was identified.

Inclusion criteria consisted of patients that had undergone bone scintigraphy at the initial onset of bone metastasis and during the following 6 months (range, 3 to 9 months) and 12 months (range, 10 to 17 months). Ex- 
clusion criteria consisted of all patients who 1) had undergone external irradiation; 2) were administered strontium 89; 3) underwent vertebroplasty or surgery; 4) delayed or discontinued zoledronic acid treatment; 5) patients suffering from other primary cancer. From 142 consecutive patients, 85 were excluded, leaving a total of 57 patients enrolled in this study. The patients' characteristics are shown in Table 1. Our institutional review board approved this retrospective clinical study, and patients' written consent was waived. This study was conducted with the approval of the hospital's ethics committee.

\subsection{Bone Scintigraphy}

Only the patients who had received ${ }^{99 \mathrm{~m}} \mathrm{Tc}-\mathrm{MDP}$ for bone scintigraphy were included in this study. ${ }^{99 \mathrm{~m}} \mathrm{Tc}$-MDP bone imaging was obtained after intravenous injection of ${ }^{99 m}$ Tc-MDP (370 to $925 \mathrm{MBq}$ (FUJI RI pharma Co. Ltd. Tokyo Japan). Bone scintigraphy was obtained about 2.5 to 3.5 hours after intravenous injection in all patients. Whole-body anterior, posterior images, and localized images were acquired utilizing 2 types of scintillation cameras (ECAM or GXA-7200; Toshiba, Tokyo Japan) with a respective capture rate of $18 \mathrm{~cm} / \mathrm{min}$ and matrix size $256 \times 1024$, and $17.5 \mathrm{~cm} / \mathrm{min}$ and matrix size $256 \times 1024$. In both cases, a parallel multichannel collimator was used. A $10 \%$ window centered on the $140-\mathrm{keV}$ peak of ${ }^{99 \mathrm{~m}}$ Tc-MDP provided energy discrimination.

\subsection{Bone Scan Index}

BSI reveals the sites, quantity, and extent of high marker uptake as a proportion of total skeletal mass demonstrating the extent of bone metastasis, which is a useful quantitative marker in bone scintigraphy [6]-[9]. BSI is defined as the percentage of the weight of summed abnormal hotspots to the entire skeleton. In order to relieve the tedium of manual calculation, we utilized the BONE $\mathrm{NAVI}^{\mathrm{TM}}$ version 1 , which automatically computes the BSI, and identifies hotspots, and quantifies hotspot intensity [10]. Planar anterior and posterior images were segmented into 12 and 10 anatomical regions, respectively and hotspots were automatically detected. Hotspots extraction and classification was performed by an artificial neural network system that subsequently computed each hotspot according to their features (e.g.: localization, shape, shape, size, counts etc.). Each hotspot was then classified as threshold-based normal or abnormal. Possible metastasis was indicated as an abnormal hotspot for computer-assisted diagnosis.

\subsection{Serum Tumor Markers Analysis, Time of Measurement}

CA15-3 and CEA serum tumor markers were measured by enzyme immunoassay in 54 patients (CA15-3) and 50 patients (CEA) at bone metastasis onset and at about 6 months (range, 3 to 9 months) and 12 months (10 to 14 months) after bone metastasis onset. The normal range of CA15-3 was 0 - $27 \mathrm{U} / \mathrm{ml}$ and CEA was 0 - 4.3 $\mathrm{ng} / \mathrm{ml}$.

\subsection{BSI and Marker Changes}

For analytical purposes, we have utilized the BSI value obtained from the bone scintigraphy at time of initial bone metastases as a reference value for each of the 57 subjects. BSI values obtained at 6 and 12 months were each divided by the reference BSI value to obtain the BSI change rate. The patients were divided in 2 distinct

\begin{tabular}{|c|c|c|}
\hline \multicolumn{3}{|c|}{ Patient characteristics } \\
\hline Number of subjects & & \\
\hline Age & \multicolumn{2}{|c|}{ Median 56 (32 - 78) } \\
\hline Survival \& death & $\begin{array}{c}\text { Survival } \\
\text { death }\end{array}$ & $\begin{array}{l}41 \\
16\end{array}$ \\
\hline Subtypes & $\begin{array}{c}\text { Luminal a or B } \\
\text { Her2 } \\
\text { Basal like } \\
\text { Unknown }\end{array}$ & $\begin{array}{c}46 \\
7 \\
3 \\
1\end{array}$ \\
\hline
\end{tabular}


groups according to their BSI change rates. Group A represents those follow-up BSI values were less than or equal $(\leq)$ to the initial BSI values after 6 and 12 months. And group B represents those follow-up BSI value was greater $(\geq)$ than the initial BSI value after 6 and 12 months. BSI change after 6 and 12 months were compared with overall survival rates. The median BSI and the median hot spots at onset of bone metastasis were also compared with survival rates. Subsequently, we divided the subjects in 2 groups according to their CA15-3/CEA changes. Group A represents those follow-up CA15-3/CEA values were less than or equal $(\leq)$ to the initial CA15-3/CEA values after 6 and 12 months. And group B represents those follow-up CA15-3/CEA value was greater $(\geq)$ than the initial CA15-3/CEA value. CA15-3/CEA change after 6 and 12 months were then compared with overall survival rates. We also compared the CA15-3 or CEA normality or abnormality at onset of bone metastasis with survival rates.

\subsection{Statistical Analysis}

All statistical analyses were performed with EZR (Saitama Medical Center, Jichi Medical University), which is a graphical user interface for R (The R Foundation for Statistical Computing, version 2.13.0). More precisely, it is a modified version of R commander (version 1.6 - 3) that includes statistical functions that are frequently used in biostatistics. And two-tailed significance level was set at $p=0.05$. The survival rate was calculated using the life table method. The Kaplan-Meier method and log-rank test assessed the single variable data analysis. Overall survival rates were calculated by the Kaplan-Meier method, starting from the day on which bone metastasis was first detected by bone scintigraphy. The final observation date was June 30, 2013. The four subjects whose survival status could not be confirmed were assumed to be alive. The follow-up period ranged from 8 months to 80 months, with a mean of 27.7 months. To confirm the factors on survival rate, univariate and multivariate analysis using Cox's proportional hazard model was used; we used the endpoint for two factors such as survival or death. We describe the calculated HR's and CI's in this article.

\section{Results}

In order to determine prognostic factors in breast cancer patients with bone metastasis, we compared with overall survival rate and following 14 parameters: 1) Patient's age at bone metastasis onset; 2) BSI change rate at 6 months and 3) 12 months after bone metastasis onset; 4) median BSI; 5) hotspot value at bone metastasis onset; 6) presence or absence of extra osseous metastasis at bone metastasis onset; 7) CA15-3 change rate at 6 months and 8) 12 months after bone metastasis onset; 9) CA15-3 normal/abnormal findings at onset of bone metastasis; 10) CEA change rate at 6 months and 11) 12 months after bone metastasis onset; 12) CEA normal/abnormal findings at bone metastasis onset; 13) Patients with/without hormone therapy; 14) Patients with/without chemotherapy.

Kaplan-Meier method and log-rank test revealed that the overall survival rate was significantly greater in group A than in those of group B after 6 months $(p=0.011)$ [Figure 1] and 12 months $(p=0.016)$ [Figure 2]. However, there was no significant difference in overall survival rates when other factors were compared. The results of Kaplan-Meier method and log-rank test are shown in Table 2.

Univariate analysis revealed that the overall survival rate was significantly greater in group A than those of group B, after a 6-month (HR: 5.841; 95\% CI 1.248 - 27.34; $p=0.025$ ) and a 12-month (HR: 4.22; 95\% CI 1.17615.15; $p=0.027$ ). A Cox’ proportional hazard model was used to assess the relationship between BSI changes after 6 month and 12 month and parameters that may affect survival rate. Refer to the sample size and the p value of univariate analysis, we selected the next parameters - patient's age, CA15-3 change after 6 month and 12 month, CEA change after 6 month and 12 months. The BSI change after 6 month was analyzed by comparing the patient's age, CA15-3 change after 6 month. Moreover the BSI change after 12 month was analyzed by comparing the patient's age, CA15-3 change after 12 month. In the multivariate analysis, BSI changes after 6 and 12 months trended toward significance with respect to parameters affecting survival rate with a HR = 12.760 (95\% CI 1.8110 - 89.850) at 6 months with a $p=0.010$ and a HR $=5.0640$ (95\% CI $1.0590-24.220)$ at 12 months with a $p=0.042$. Only the BSI changes after 6 and 12 months appear to be significant factors correlating with patients' survival rate. The results of multivariate analysis are shown in Table 3.

\section{Discussion}

Bone metastasis is a relatively common location for distant metastases in breast cancer patients and an early as 


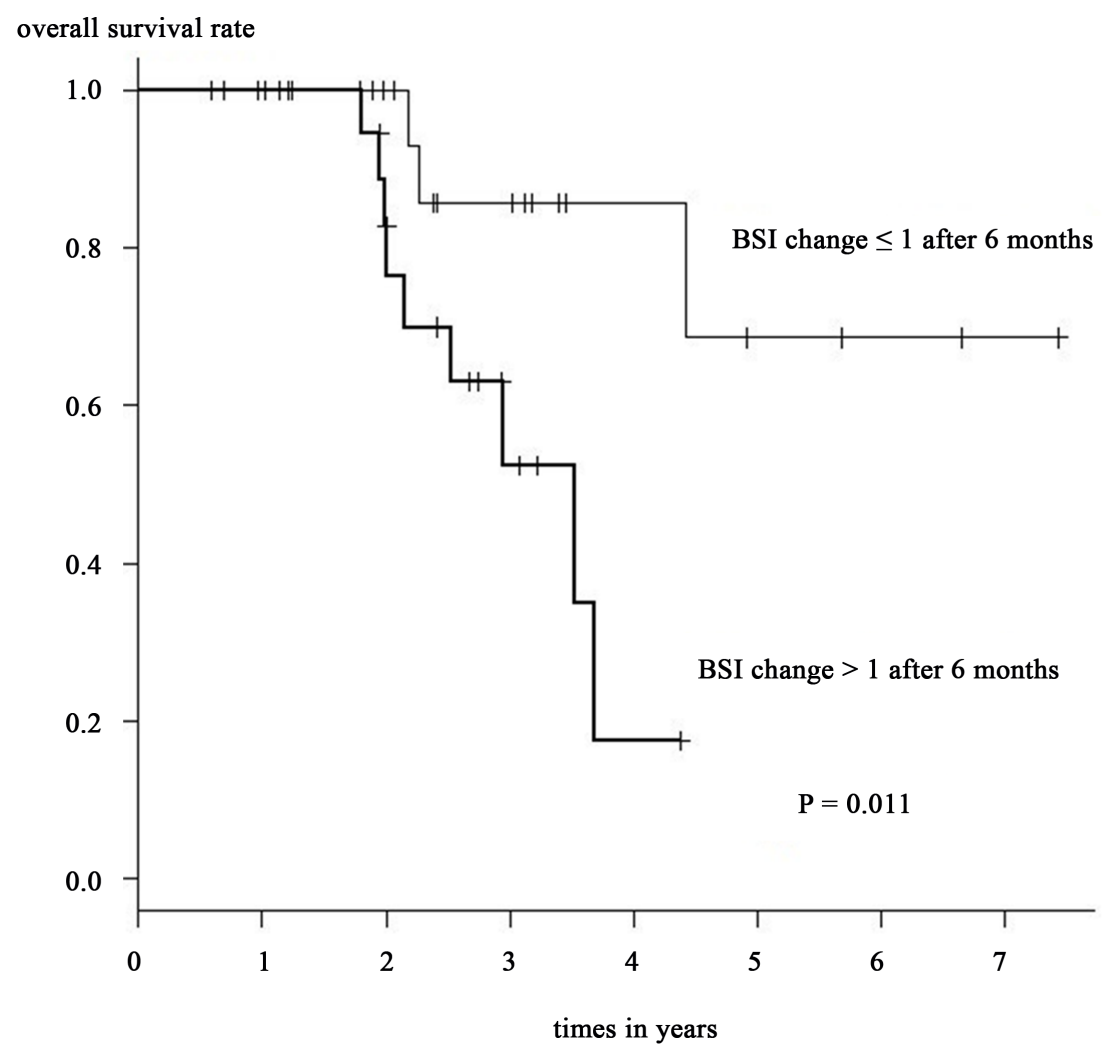

Figure 1. BSI change after 6 months and overall survival rate.

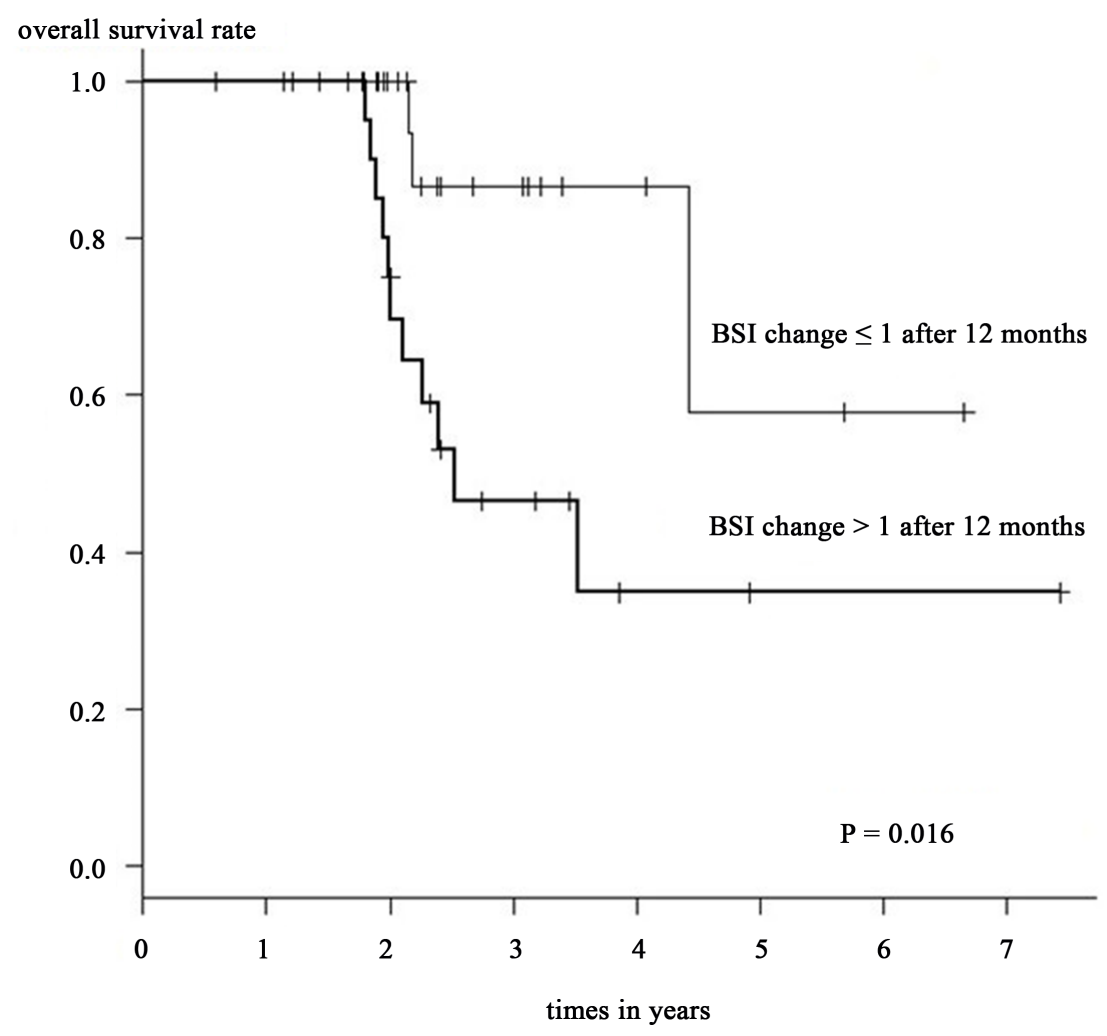

Figure 2. BSI change after 12 months and overall survival rate. 
Table 2. Overall survival and log rank test.

\begin{tabular}{|c|c|c|c|c|}
\hline Variable & & No of patients & No of deaths & $p$ value (Log Rank Test) \\
\hline $\begin{array}{c}\text { Age } \\
\text { (median 56) }\end{array}$ & $\begin{array}{l}\leq 56 \\
\geq 56\end{array}$ & $\begin{array}{l}28 \\
29\end{array}$ & $\begin{array}{l}7 \\
9\end{array}$ & 0.374 \\
\hline $\begin{array}{l}\text { BSI change after } \\
6 \text { months }\end{array}$ & $\begin{array}{l}\leq 1 \\
\geq 1\end{array}$ & $\begin{array}{l}20 \\
23\end{array}$ & $\begin{array}{l}2 \\
9\end{array}$ & $0.011^{*}$ \\
\hline $\begin{array}{l}\text { BSI change after } \\
12 \text { months }\end{array}$ & $\begin{array}{l}\leq 1 \\
\geq 1\end{array}$ & $\begin{array}{l}25 \\
23\end{array}$ & $\begin{array}{c}3 \\
11\end{array}$ & $0.016^{*}$ \\
\hline $\begin{array}{l}\text { The number of BSI } \\
\text { (median 0.676) }\end{array}$ & $\begin{array}{l}\leq 0.676 \\
\geq 0.676\end{array}$ & $\begin{array}{l}28 \\
29\end{array}$ & $\begin{array}{l}8 \\
8\end{array}$ & 0.743 \\
\hline $\begin{array}{l}\text { The number of hot spots } \\
\text { (median 7) }\end{array}$ & $\begin{array}{l}\leq 7 \\
\geq 7\end{array}$ & $\begin{array}{l}30 \\
27\end{array}$ & $\begin{array}{c}10 \\
6\end{array}$ & 0.644 \\
\hline $\begin{array}{l}\text { Extra osseous metastasis } \\
\text { at bone metastasis onset }\end{array}$ & $\begin{array}{l}\text { presence } \\
\text { absence }\end{array}$ & $\begin{array}{l}31 \\
26\end{array}$ & $\begin{array}{l}7 \\
9\end{array}$ & 0.986 \\
\hline $\begin{array}{l}\text { CA15-3 change after } \\
6 \text { months }\end{array}$ & $\begin{array}{l}\leq 1 \\
\geq 1\end{array}$ & $\begin{array}{l}28 \\
20\end{array}$ & $\begin{array}{l}6 \\
7\end{array}$ & 0.364 \\
\hline $\begin{array}{l}\text { CA15-3 change after } \\
12 \text { months }\end{array}$ & $\begin{array}{l}\leq 1 \\
\geq 1\end{array}$ & $\begin{array}{l}29 \\
18\end{array}$ & $\begin{array}{l}4 \\
7\end{array}$ & 0.0534 \\
\hline $\begin{array}{l}\text { CA15-3 normal or abnormal } \\
\text { at bone metastasis onset }\end{array}$ & $\begin{array}{c}\text { normal } \\
\text { abnormal }\end{array}$ & $\begin{array}{l}25 \\
29\end{array}$ & $\begin{array}{l}7 \\
7\end{array}$ & 0.894 \\
\hline $\begin{array}{l}\text { CEA change after } \\
6 \text { months }\end{array}$ & $\begin{array}{l}\leq 1 \\
\geq 1\end{array}$ & $\begin{array}{l}24 \\
17\end{array}$ & $\begin{array}{l}5 \\
6\end{array}$ & 0.405 \\
\hline $\begin{array}{l}\text { CEA change after } \\
12 \text { months }\end{array}$ & $\begin{array}{l}\leq 1 \\
\geq 1\end{array}$ & $\begin{array}{l}27 \\
17\end{array}$ & $\begin{array}{l}5 \\
6\end{array}$ & 0.144 \\
\hline $\begin{array}{l}\text { CEA normal or abnormal } \\
\text { at bone metastasis onset }\end{array}$ & $\begin{array}{c}\text { normal } \\
\text { abnormal }\end{array}$ & $\begin{array}{l}28 \\
22\end{array}$ & $\begin{array}{l}7 \\
6\end{array}$ & 0.968 \\
\hline $\begin{array}{l}\text { With hormone therapy or } \\
\text { without hormone therapy }\end{array}$ & $\begin{array}{l}\text { without } \\
\text { with }\end{array}$ & $\begin{array}{l}20 \\
37\end{array}$ & $\begin{array}{l}8 \\
7\end{array}$ & 0.50 \\
\hline $\begin{array}{l}\text { With anticancer drug or } \\
\text { without anticancer drug. }\end{array}$ & $\begin{array}{l}\text { without } \\
\text { with }\end{array}$ & $\begin{array}{l}19 \\
38\end{array}$ & $\begin{array}{c}3 \\
13\end{array}$ & 0.301 \\
\hline
\end{tabular}

CA15-3: serum cancer antigen 15-3; CEA: carcinoembryonic antigen

Table 3. Univariate and multivariate analysis of survival.

\begin{tabular}{|c|c|c|c|c|}
\hline \multirow{2}{*}{ Variable } & \multicolumn{2}{|c|}{ Univariate analysis } & \multicolumn{2}{|c|}{ Multivariate analysis } \\
\hline & HR (95\%CI) & $p$ value & HR (95\%CI) & $p$ value \\
\hline Age & $\begin{array}{c}1.469 \\
(0.5446-3.962)\end{array}$ & 0.4476 & $\begin{array}{c}\text { after } 6 \text { months } \\
1.0720 \\
(1.00-1.146) \\
\text { after } 12 \text { months } \\
0.9955 \\
(0.9426-1.051)\end{array}$ & $0.04^{*}$ \\
\hline $\begin{array}{c}\text { BSI change after } \\
6 \text { months }(\leq 1 \text { vs. } \geq 1)\end{array}$ & $\begin{array}{c}5.841 \\
(1.248-27.34)\end{array}$ & $0.025^{*}$ & $\begin{array}{c}12.76 \\
(1.811-89.850)\end{array}$ & $0.01^{*}$ \\
\hline $\begin{array}{c}\text { BSI change after } \\
12 \text { months }(\leq 1 \text { vs. } \geq 1)\end{array}$ & $\begin{array}{c}4.22 \\
(1.176-15.15)\end{array}$ & $0.027^{*}$ & $\begin{array}{c}5.0640 \\
(1.0590-24.220)\end{array}$ & $0.042^{*}$ \\
\hline $\begin{array}{l}\text { The number of BSI } \\
\text { ( } \leq \text { median vs. } \geq \text { median) }\end{array}$ & $\begin{array}{c}0.8479 \\
(0.3177-2.263)\end{array}$ & 0.7418 & & \\
\hline $\begin{array}{l}\text { The number of hot spots } \\
\text { ( } \leq \text { median vs. } \geq \text { median) }\end{array}$ & $\begin{array}{c}0.7881 \\
(0.2861-2.171)\end{array}$ & 0.6451 & & \\
\hline $\begin{array}{l}\text { Extraosseous metastasis } \\
\text { at bone metastasis onset }\end{array}$ & $\begin{array}{c}0.935 \\
(0.3233-2.704)\end{array}$ & 0.9013 & & \\
\hline $\begin{array}{l}\text { CA15- } 3 \text { change after } \\
6 \text { months ( } \leq 1 \text { vs. } \geq 1)\end{array}$ & $\begin{array}{c}1.652 \\
(0.5524-4.939)\end{array}$ & 0.3692 & $\begin{array}{c}0.9554 \\
(0.2661-3.413)\end{array}$ & 0.944 \\
\hline
\end{tabular}


Continued

\begin{tabular}{|c|c|c|c|c|}
\hline $\begin{array}{l}\text { CA15- } 3 \text { change after } \\
12 \text { months }(\leq 1 \text { vs. } \geq 1)\end{array}$ & $\begin{array}{c}3.167 \\
(0.9223-10.88)\end{array}$ & 0.067 & $\begin{array}{c}2.207 \\
(0.6413-7.599)\end{array}$ & 0.209 \\
\hline $\begin{array}{l}\text { CA15-3 normal or abnormal } \\
\text { at bone metastasis onset }\end{array}$ & $\begin{array}{c}0.931 \\
(0.3244-2.672)\end{array}$ & 0.8943 & & \\
\hline $\begin{array}{l}\text { CEA change after } \\
6 \text { months }(\leq 1 \text { vs. } \geq 1)\end{array}$ & $\begin{array}{c}1.687 \\
(0.4866-5.846)\end{array}$ & 0.4098 & & \\
\hline $\begin{array}{l}\text { CEA change after } \\
12 \text { months }(\leq 1 \text { vs. } \geq 1)\end{array}$ & $\begin{array}{c}2.377 \\
(0.7183-7.869)\end{array}$ & 0.1562 & & \\
\hline $\begin{array}{l}\text { CEA normal or abnormal } \\
\text { at bone metastasis onset }\end{array}$ & $\begin{array}{c}1.023 \\
(0.3407-3.071)\end{array}$ & 0.9679 & & \\
\hline $\begin{array}{l}\text { With hormone therapy } \\
\text { or without hormone therapy }\end{array}$ & $\begin{array}{c}1.023 \\
(0.3407-3.071)\end{array}$ & 0.9679 & & \\
\hline $\begin{array}{l}\text { With anticancer drug or } \\
\text { without anticancer drug. }\end{array}$ & $\begin{array}{c}1.909 \\
(0.5378-6.775)\end{array}$ & 0.3172 & & \\
\hline
\end{tabular}

CA15-3: serum cancer antigen 15-3; CEA: carcinoembryonic antigen.

well as accurate diagnosis is essential in order to select the appropriate treatment management. Changes in tumor size after treatment are often, but not invariably, related to duration of survival. Currently, CT and MRI are the best available and most reproducible methods to measure and diagnose lesions using the Response Evaluation Criteria in Solid Tumors (RECIST) criteria [11]. However, RECIST is only applicable in osteolytic lesions with an identifiable soft tissue component [12] making the evaluation of the therapeutic effect for bone metastasis difficult, especially in osteoblastic and combined bone metastasis. On the other hand, the degree and extent of bone metastases determine the survival prognosis [13] and yet, there is no useful technique quantifying the skeletal tumor burden. Bone scintigraphy however, is a widely used screening tool for the diagnosis of bone metastasis and also for assessing skeletal tumor burden in the bone as a percentage of the total skeletal mass for prostate cancer patients. BSI was developed as a quantitative tool to improve the interpretability and clinical relevance of the bone scintigraphy [9]. However, this imaging modality does not appear to provide the appropriate information on bone lesions nor does it adequately measure bone lesions, hence limiting this technique to the mere confirmation of presence or absence of bone lesions. Bone scintigraphy diagnosis mainly relies on visual evaluation and lacks diagnostic objectivity and specificity, with indeterminate results often prompting the need for further imaging. To mitigate this shortcoming and improve the usefulness of BSI, several commercially available CAD software including BONE NAVI ${ }^{\mathrm{TM}}$ version 1 have been developed and are a fully automated method of quantifying BSI. BONE NAVI ${ }^{\mathrm{TM}}$ version 1 automatically computes BSI and demonstrates the extent and quantitative aspects of bone metastases relieving the burden of visual measurement. In an instructive study, conventional visual assessment of bone metastases exhibited a $77 \%$ sensitivity and $95 \%$ specificity, while BONE NAVI $^{\mathrm{TM}}$ version 1 evaluation not only improved the sensitivity to 88\% with a specificity of 94\% but also significantly improved inter-observer agreement [10]. It is worth mentioning however, that CAD’s performance greatly depends on an artificial neural network that has acquired 'knowledge' from an accumulated database. In the Japanese version of BONE NAVI ${ }^{\mathrm{TM}}$ version 1 a little over 900 Japanese patients' bone scintigraphies were incorporated within the database and have resulted in a reported significant increase of specificity from $57 \%$ to $81 \%$ [10]. We utilized BONE NAVI ${ }^{\mathrm{TM}}$ version 1 for quantitative analysis. The BSI is a mean of captured bone scintigraphy data as a single reproducible quantitative measure, thus allowing bone scintigraphy to be explored as an imaging biomarker. An excellent review evaluating the prognostic factors of BSI and prostate-specific antigen (PSA) in prostate cancer patients, suggested that the changes in BSI appeared to be a better predicting factor of patient survival than the observed changes in PSA [7]. Furthermore, a separate study involving prostate cancer patients with bone metastasis revealed that there was no significant difference in the overall survival rate in patients with a $\mathrm{BSI}<3$ and $\mathrm{BSI} \geq 3$, but a significant difference in overall survival rate was observed between patients whose BSI decreased and those who did not [7].

In this study, we originally hypothesized that the amount of hotspots might be a prognostic parameter in both breast and prostate cancer however, neither BSI values nor the amount of hotspots were conclusively identified as possible prognostic factors in breast cancer with bone metastases. It has not yet been determined why BSI changes correlated with the overall survival rate; however, since breast cancer is a systemic disease, we surmise that bone metastasis reflects the systemic tumor burden and may not be directly linked to survival in breast can- 
cer. Hence, it may be possible that an increase in the BSI value could result in an increase in tumor burden and development of metastases in other sites such as the lungs, liver, and brain, leading to deterioration and ultimately cancer death.

Serum tumor markers have been used as a biomarker of systemic therapy response and also play a role as prognostic biomarkers. Among them, CA15-3, CEA, NCC-ST-439, and BCA225 are well-established tumor markers used for breast cancer. In particular, many reports suggest a greater usefulness of CA 15-3 in monitoring advanced breast cancer compared with CEA, which is a better prognostic factor [14]. CA15-3 is reported to be a more sensitive marker with a pre-treatment positivity rate significantly higher than CEA for breast cancer [15]-[19]. However, in contrast our results did not provide any evidence that CA15-3 and CEA were useful prognostic indicators in breast cancer with bone metastasis.

Interestingly, a previous study from Iwase et al. demonstrated that changes in BSI significantly correlated with skeletal-related-event (SRE) incidence, hence concluding that BSI was a useful imaging biomarker for SRE in bone metastasis treatment of breast cancer as well as being a potential predictor of SRE [20]. However their results did not show any correlation between BSI changes and survival rates. We believe that their population sample may have played a role in this discrepancy. In fact, only $65 \%$ of their subjects utilized bone modifying agents. Furthermore, there was no clear mention of whether they were treated with zoledronic acid which was, at the time, the consented treatment management. In contrast, the entirety of our patient sample was treated with zoledronic acid which has been reported to significantly reduce skeletal complications when compared to placebo in breast cancer with bone metastases [21] and has now become the recommended treatment for bone metastasis [22].

Changes in BSI were revealed to be a potential predicting factor that carried prognostic value at 6 and 12 months after the detection of bone metastasis. BSI changes may be a valid prognostic factor for breast cancer, or otherwise stated, BSI could potentially serve as a breast cancer biomarker and therefore could be used to evaluate bone metastasis and provide prognostic information for therapeutic outcomes.

However, there are limitations to this study. There is the presence of a time interval between bone scintigraphy and blood serum examination. Moreover, the follow-up time is short especially regarding BSI change after 6 months. As of June 30, 2015, no additional death was observed in group A whereas group B demonstrated 1 additional death after 6 months. We think that this limitation does not affect our original data. But, the most important limitation is retrospective nature of the study and its small sample size. A large-scale prospective study is necessary.

\section{Conclusion}

When performing bone scintigraphy in breast cancer patients with bone metastasis, the use of CAD can provide in-depth evaluation that could potentially help determine the course of treatment. In this study, the amount of BSI change at 6 and 12 months after the onset of bone metastasis appears to be a prognostic factor in breast cancer patients with bone metastasis which could then be addressed more efficiently and consequently result in improved prognosis.

\section{Acknowledgements}

We thank Professor Kenichi Nakajima of Kanazawa University Department of Nuclear Medicine and Director of Diagnostic Radiology Hiroyuki Horikoshi of Gunma Prefectural Cancer Center Director for their assistance in this research.

\section{Conflicts of Interest}

All authors have no conflicts of interest in this study.

\section{References}

[1] Makita, M., Iwase, T., Tada, T., Takahashi, K., Tada, K., Nishimura, S., Yoshimoto, M., Kasumi, F., Akiyama, F. and Sakamoto, G. (2004) The Site and Timing of the First Recurrence of Breast Cancer. Japanese Journal of Breast Cancer, 19, 343-351.

[2] Pivot, X., Asmar, L., Hortobagyi, G.N., Theriault, R., Pastorini, F. and Buzdar, A.R. (2003) Retrospective Study of 
First Indicators of Breast Cancer. Breast Cancer, 10, 335-340.

[3] Brennan, M.E. and Houssami, N. (2012) Evaluation of the Evidence on Staging Imaging for Detection of Asymptomatic Distant Metastases in Newly Diagnosed Breast Cancer. Breast, 21, 112-123. http://dx.doi.org/10.1016/j.breast.2011.10.005

[4] Myers, R.E., Johnstion, M., Pritchard, K., Levine, M. and Oliver, T. (2001) Breast Cancer Disease Site Group of the Cancer Care Ontario Practice Guidelines Initiative. Baseline Staging Tests in Primary Breast Cancer: A Practice Guideline. CMAJ, 164, 1439-1444.

[5] Sadik, M., Suurkula, M., Hoglund, P., Jarund, A. and Edenbrandt, L. (2009) Improved Classifications of Planar Whole Body Bone Scans Using a Computer-Assisted Diagnosis System a Multicenter, Multiple-Reader, Multiple-Case Study. The Journal of Nuclear Medicine, 50, 368-375. http://dx.doi.org/10.2967/jnumed.108.058883

[6] Erdi, Y.E., Humm, J.L., Lmbriaco, M., Yeung, H. and Larson, S.M. (1997) Quantitative Bone Metastases Analysis Based on Image Segmentation. The Journal of Nuclear Medicine, 38, 1401-1406.

[7] Mitsui, Y., Shiina, H., Yamamoto, Y., Haramoto, M., Arichi, N., Yasumoto, H., Kitagaki, H. and Igawa, M. (2012) Prediction of Survival Benefit Using an Automated Bone Scan Index in Patients with Castration-Resistant Prostate Cancer. BJU International, 110, E628-E634. http://dx.doi.org/10.1111/j.1464-410X.2012.11355.x

[8] Imbriaco, M., Larson, S.M., Yeung, H.W., Mawlawi, O.R., Erdi, Y., Venkatraman, E.S. and Scher, H.I. (1998) A New Parameter for Measuring Metastatic Bone Involvement by Prostate Cancer the Bone Scan Index. Clinical Cancer Research, 4, 1765-1772.

[9] Dennis, E.R., Jia, X., Mezheritskiy, I.S., Stephenson, R.D., Schoder, H., Fox, J.J., Heller, G., Scher, H.I., Larson, S.M. and Morris, M.J. (2012) Bone Scan Index: A Quantitative Treatment Response Biomarker for Castration-Resistant Metastatic Prostate Cancer. Journal of Clinical Oncology, 30, 519-524. http://dx.doi.org/10.1200/JCO.2011.36.5791

[10] Horikoshi, H., Kikuchi, A. and Onoguch, M. (2012) Computer-Aided Diagnosis System for Bone Scintigrams from Japanese Patients: Importance of Training Database. Annals of Nuclear Medicine, 26, 622-626. http://dx.doi.org/10.1007/s12149-012-0620-5

[11] Suzuki, C., Jacobsson, H., Hatschek, T., Torkzad, M.R., Bodén, K., Eriksson-Alm, Y., Berg, E., Fujii, H., Kubo, A. and Blomqvist, L. (2008) Radiologic Measurements of Tumor Response to Treatment: Practical Approaches and Limitations. RadioGraphics, 28, 329-344. http://dx.doi.org/10.1148/rg.282075068

[12] Eisenhauer, E.A., Therasse, P., Bogaerts, J., Schwartz, L.H., Sargent, D., Ford, R., Dancey, J., Arbuck, S., Gwyther, S., Mooney, M., Rubinsten, L., Shankar, L., Dodd, L., Kaplan, R., Lacombe, D. and Verweji, J. (2009) New Response Evaluation Criteria in Solid Tumours: Revised RECIST Guideline (Version 1.1). European Journal of Cancer, 45, 228-247. http://dx.doi.org/10.1016/j.ejca.2008.10.026

[13] Soloway, M.S., Hardeman, S.W. and Hickey, D. (1998) Stratification of Patients with Metastatic Prostate Cancer Based on Extent of Disease on Initial Bone Scan. Cancer, 61, 195-202. http://dx.doi.org/10.1002/1097-0142(19880101)61:1<195::AID-CNCR2820610133>3.0.CO;2-Y

[14] Colomer, R., Rubal, A., Genollá, J., Rubio, D., Del Campo, J.M., Bodi, R. and Salvador, L. (1993) Circulating CA 15-3 Levels in the Postsurgical Follow-Up and in Monitoring Clinical Course of Metastatic Cancer in Patients with Breast Carcinoma. European Journal of Surgical Oncology, 19, 74-79.

[15] Safi, F., Kohler, J., Rottinger, E. and Beger, H. (1991) The Value of the Tumor Marker CA 15-3 in Diagnosing and Monitoring Breast Cancer. A Comparative Study with Carcinoembryonic Antigen. Cancer, 68, 574-582. http://dx.doi.org/10.1002/1097-0142(19910801)68:3<574::AID-CNCR2820680322>3.0.CO;2-B

[16] Kokko, R., Holli, K. and Hakama, M. (2002) Ca 15-3 in the Follow-Up of Localized Breast Cancer: A Prospective Study. European Journal of Cancer, 38, 1189-1193. http://dx.doi.org/10.1016/S0959-8049(01)00429-4

[17] Harris, L., Fritsche, H., MAennel, R., Norton, L., Ravdin, P., Taube, S., Somerfield, M.R., Hayes, D.F. and Best Jr., R.C. (2007) American Society of Clinical Oncology 2007 Update of Recommendations for the Use of Tumor Markers in Breast Cancer. Journal of Clinical Oncology, 25, 5287-5312. http://dx.doi.org/10.1200/JCO.2007.14.2364

[18] Best, R.C. (2000) 2000 Update of Recommendations for the Use of Tumor Markers in Breast and Colorectal Cancer: Clinical Practice Guidelines of American Society of Clinical Oncology. Journal of Clinical Oncology, 19, 1865-1878.

[19] Kurebayashi, J., Yamamoto, Y., Tanaka, K., Kohno, N., Kurosumi, M., Moriya, T., Nishimura, R., Ogawa, Y. and Taguchi, T. (2003) Significance of Serum Carcinoembryonic Antigen and CA 15-3 in Monitoring Advanced Breast Cancer Patients Treated with Systemic Therapy: A Large-Scale Retrospective Study. Breast Cancer, 10, 38-44. http://dx.doi.org/10.1007/BF02967624

[20] Iwase, T., Yamamoto, N., Ichihara, H., Togawa, T., Nagashima, T. and Miyazaki, M. (2014) The Relationship between Skeletal-Related Events and Bone Scan Index for the Treatment of Bone Metastasis with Breast Cancer Patients. Medicine, 93, e269. http://dx.doi.org/10.1097/md.0000000000000269

[21] Kohno, N., Aogi, K., Minami, H., Nakamura, S., Asaga, T., Iino, Y., Watanabe, T., Goessl, C., Ohashi, Y. and Taka- 
shima, S. (2005) Zoledronic Acid Significantly Reduces Skeletal Complications Compared with Placebo in Japanese Women with Bone Metastases from Breast Cancer: A Randomized, Placebo-Controlled Trial. Journal of Clinical Oncology, 23, 3314-3321. http://dx.doi.org/10.1200/JCO.2005.05.116

[22] Berenson, J.R. (2005) Recommendations for Zoledronic Acid Treatment of Patients with Bone Metastasis. Oncologist, 10, 52-62. http://dx.doi.org/10.1634/theoncologist.10-1-52 